\title{
Selenium improves stem cell potency by stimulating the proliferation and active migration of 3T3-L1 preadipocytes
}

\author{
SHIN-HYUNG PARK ${ }^{1 *}$, JEONG-HWAN KIM ${ }^{3 *}$, SOO-WAN NAM ${ }^{3,5}$, BYUNG-WOO KIM ${ }^{3,4,6}$, \\ GI-YOUNG KIM ${ }^{7}$, WUN-JAE KIM ${ }^{8}$ and YUNG HYUN $\mathrm{CHOI}^{2-4}$
}

\begin{abstract}
Departments of ${ }^{1}$ Pathology and ${ }^{2}$ Biochemistry, Dongeui University College of Oriental Medicine, Busan 614-052;
${ }^{3}$ Blue-Bio Industry RIC, ${ }^{4}$ Anti-Aging Research Center, Departments of ${ }^{5}$ Biotechnology and Bioengineering, and ${ }^{6}$ Life Science and Biotechnology, Dongeui University, Busan 614-714; ${ }^{7}$ Laboratory of Immunobiology,

Department of Marine Life Sciences, Jeju National University, Jeju 690-756; ${ }^{8}$ Department of Urology

and Personalized Tumor Engineering Research Center, College of Medicine,

Chungbuk National University, Cheongju 361-763, Republic of Korea
\end{abstract}

Received August 8, 2013; Accepted October 23, 2013

DOI: 10.3892/ijo.2013.2182

\begin{abstract}
Selenium is a trace nutrient element that protects cells against oxidative damage. In this study, the potential of selenium to improve stem cell potency through active proliferation and migration of 3T3-L1 preadipocytes was investigated, together with the underlying molecular mechanisms. The results indicated that selenium applied for $24 \mathrm{~h}$ stimulated cell proliferation up to $20 \%$ compared to untreated control cells. Selenium induced the expression of cyclin-dependent kinase (CDK) 1 and CDK2, which are known to regulate G2/M progression, and significantly downregulated the CDK inhibitors p21 and p27. Selenium also activated the expression of the phosphatidylinositol 3-kinase (PI3K)/Akt pathway, as well as extracellular signal-regulated kinase (ERK). Although LY294002, an inhibitor of PI3K, significantly inhibited the selenium-induced cell proliferation of the 3T3-L1 preadipocytes, PD98059, an inhibitor of ERK, did not affect selenium-induced active proliferation. These results clearly indicate that selenium stimulated cell proliferation through cell cycle progression and PI3K/Akt activation, but not through ERK activation. Furthermore, selenium increased 3T3-L1 cell migration, which was associated with the induction of matrix metalloproteinase (MMP)-2 and MMP-9. Taken together, the current findings suggest that selenium can stimulate stem cell
\end{abstract}

Correspondence to: Dr Yung Hyun Choi, Department of Biochemistry, Dongeui University College of Oriental Medicine, Yangjeong-dong San 45, Busanjin-gu, Busan 614-052, Republic of Korea

E-mail: choiyh@deu.ac.kr

*Contributed equally

Key words: selenium, 3T3-L1 adipocytes, proliferation, migration, stem cell potency potency by increasing the proliferation and active migration of 3T3-L1 cells.

\section{Introduction}

Induced pluripotent stem cells (IPSCs) are derived from nonpluripotent cells, such as adult somatic cells; they include fibroblasts, adipocytes and keratinocytes (1-3). IPSCs are similar to embryonic stem cells (ESCs) in their capacity to renew themselves, differentiate into various cell types and migrate actively (4). Studies have reported that various intracellular and extracellular factors activate multiple signaling networks during the increase in cell proliferation to generate active self-renewal activity. For example, Welham et al (5) reported that phosphoinositide 3-kinase (PI3K) and glycogen synthase kinase 3 are important in ESC proliferation and pluripotency. Lee et al (6) revealed that the self-renewal of ESCs is dependent on PI3K/Akt, Smad and Wnt signaling pathways. The PI3K/Akt signaling pathway has also been reported to play a pivotal role in the induction of pluripotent cells from primordial germ cells and ESCs $(7,8)$.

Selenium is a trace nutrient element that is involved in many biochemical pathways. It protects cells against oxidative damage by optimizing the activity of glutathione peroxidase and thioredoxin reductase, as well as several other selenoproteins $(9,10)$. It has been reported to have anticarcinogenic effects by preventing oxidative damage, regulating immune responses and inducing apoptosis (11-13). Studies have also found that selenium has preventive effects in cardiovascular diseases, viral infections, fertility and aging $(10,14)$. More recently, selenium was shown to induce stem cell behavior in human adipose-tissue stromal cells (15).

Although IPSCs can be an attractive target to develop regenerative medicines for aplastic diseases, the molecular mechanisms regulating their pluripotency, proliferation and differentiation are not fully understood. Thus, in the present study, we investigated whether selenium, as an extracellular factor, can improve the potency of stem cells by stimulating 
the proliferation and migration of 3T3-L1 preadipocytes. We also investigated the mechanisms underlying its activity. In the process, we demonstrated that selenium plays a key role in the self-renewal activity of stem cells via cell cycle progression and the activation of the PI3K/Akt signaling pathway.

\section{Materials and methods}

Reagents and antibodies. Dulbecco's modified Eagle's medium (DMEM), bovine calf serum (BCS), Dulbecco's phosphate buffered saline (DPBS), and $1 \%$ penicillin-streptomycin were purchased from Gibco-BRL (Gaithersburg, MD, USA). Selenium, trypan blue, paraformaldehyde and toluidine blue $\mathrm{O}$ were purchased from Sigma-Aldrich Chemical Co. (St. Louis, MO, USA). LY294002 and PD98059 were obtained from Calbiochem (San Diego, CA, USA). All primers were purchased from Bioneer Co. (Daejeon, Korea), and all primary and secondary antibodies were obtained from Santa Cruz Biotechnology (Santa Cruz, CA, USA) except p-Akt antibody and p-ERK antibody (Cell Signaling Technology, Beverly, MA, USA). All other chemicals not specifically mentioned here were obtained from Sigma-Aldrich.

Cell culture and selenium treatment. Mouse 3T3-L1 preadipocytes (American Type Culture Collection, Rockville, MD, USA) were cultured at $37^{\circ} \mathrm{C}$ in humidified $95 \%$ air and $5 \% \mathrm{CO}_{2}$ in DMEM with $10 \%$ BCS and $1 \%$ penicillin-streptomycin. Selenium was dissolved in sterilized distilled water and stored at $-20^{\circ} \mathrm{C}$. For selenium treatment, 3T3-L1 cells were seeded and stabilized for $24 \mathrm{~h}$. The cells were then treated with selenium at various concentrations in serum-free DMEM for different time-points. Then the optimum concentration of selenium was selected on the basis of cell viability studies using the trypan blue exclusion assay.

Trypan blue exclusion assay. 3T3-L1 cells were seeded in 6 -well plates at a density of $7 \times 10^{4}$ cells per well and incubated for $24 \mathrm{~h}$. The medium was then replaced with serum-free DMEM containing different concentrations of selenium. Following incubation for another $24 \mathrm{~h}$, cells were collected and viable cells were counted with a hematocytometer by excluding the stained cells with $0.4 \%$ trypan blue dye. Triplicate wells were used in all cell viability assays and each experiment was repeated at least three times.

Colony-forming cell assay. 3T3-L1 cells were seeded in 10-cm cell culture dishes at a density of $3 \times 10^{3}$ and stabilized for $24 \mathrm{~h}$. Following stimulation with selenium $(15 \mathrm{ng} / \mathrm{ml})$ for another $24 \mathrm{~h}$ in serum-free DMEM, media was replaced with fresh media containing $10 \%$ BCS. After 15 days, the culture media was discarded and the attached cells were fixed with $4 \%$ paraformaldehyde. Then the cells were stained with $0.1 \%$ toluidine blue $\mathrm{O}$ in $1 \%$ paraformaldehyde for 3 days. After washing with distilled water several times, we determined the proliferation efficiency by counting the visual colonies.

Cell migration assay. To evaluate the migration activity of selenium-treated 3T3-L1 cell, we conducted a simple cellscraped wound model assay. Cells were seeded in $35-\mathrm{mm}$ cell culture dishes at a density of $1.5 \times 10^{5}$ and stabilized for $24 \mathrm{~h}$.
Then cells were scraped in a straight line across the dish using $200 \mu \mathrm{l}$ tips and washed with fresh media for three times. After incubation with selenium $(15 \mathrm{ng} / \mathrm{ml})$ for $24 \mathrm{~h}$ in serum-free DMEM, the migrated cells onto the wounded region were photographed under the microscope at $\mathrm{x} 40$ magnification.

Protein extraction and western blot analysis. Seleniumtreated 3T3-L1 cells were collected and lysed with lysis buffer [25 mM Tris-Cl (pH 7.5), $250 \mathrm{mM} \mathrm{NaCl,} 5 \mathrm{mM}$ EDTA, $1 \%$ NP-40, $1 \mathrm{mM}$ phenymethylsulfonyl fluoride (PMSF), $5 \mathrm{mM}$ dithiothreitol (DTT)]. Then the protein concentrations were quantified using a Bio-Rad protein assay (Bio-Rad Lab., Hercules, CA, USA) according to the manufacturer's instructions. For western blot analysis, an equal amount of protein was loaded on SDS-polyacrylamide gel and transferred onto a nitrocellulose membrane (Schleicher \& Schuell, Keene, NH, USA) by electroblotting. The blots were then probed with the specific primary antibodies and incubated overnight at $4^{\circ} \mathrm{C}$. Following $1 \mathrm{~h}$ of incubation with the secondary antibodies, the blots were visualized by enhanced chemiluminescence (ECL, Amersham) according to the manufacturer's procedure.

Statistical analysis. All data are presented as the mean \pm SD from at least three independent experiments. Statistical significance of the differences between groups was calculated using the Student's two tailed t-test.

\section{Results}

Selenium stimulates the cell growth and the proliferation of 3T3-L1 preadipocytes. As stem cells have self-renewal activity demonstrated by enhanced cell proliferation, we first investigated the effects of selenium on the growth of the 3T3-L1 cells. To evaluate the degree of proliferation, a trypan blue exclusion assay was performed following treatment with various concentrations of selenium for $72 \mathrm{~h}$. As shown in Fig. 1A, the selenium treatment enhanced the cell growth, with $15 \mathrm{ng} / \mathrm{ml}$ of selenium the most effective in stimulating cell proliferation among various concentrations of selenium tested. The proliferative action of selenium $(15 \mathrm{ng} / \mathrm{ml})$ lasted $72 \mathrm{~h}$, although the effect was more significant at $24 \mathrm{~h}$. Microscopic observations of selenium-treated cells revealed active proliferation compared with untreated control cells (Fig. 1B). Thus, the application of $15 \mathrm{ng} / \mathrm{ml}$ of selenium for $24 \mathrm{~h}$ was determined to be the optimal treatment for further study. In addition, the selenium-treated cells formed more colonies, showing an 1.4-fold increase compared with the control cells (Fig. 2). These results clearly indicate that selenium induced active cell proliferation of the 3T3-L1 cells.

Selenium stimulated the cell cycle progression of 3T3-L1 preadipocytes. Cell cycle progression is critically regulated by a sequential activation of cyclin-dependent kinase (CDKs), the activities and specificities of which are determined by phosphorylation of their corresponding catalytic subunits and by their associations with Cdks inhibitors and cyclins, which are differentially expressed during the cell cycle. CDK4 and CDK6 modulate the G1/S checkpoint by binding D-type cyclins. In addition to regulating the $\mathrm{G} 1 / \mathrm{S}$ checkpoint by interacting with cyclin E, CDK2, together with cyclin A, controls the S phase 


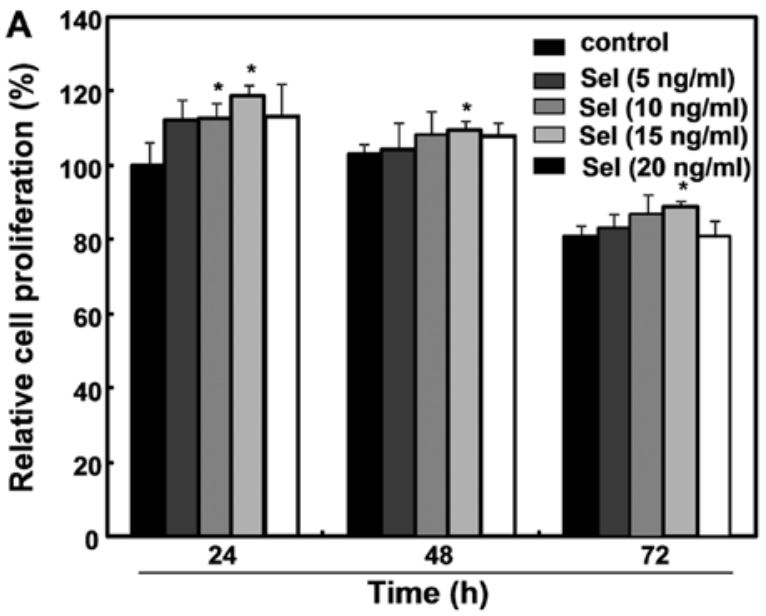

B

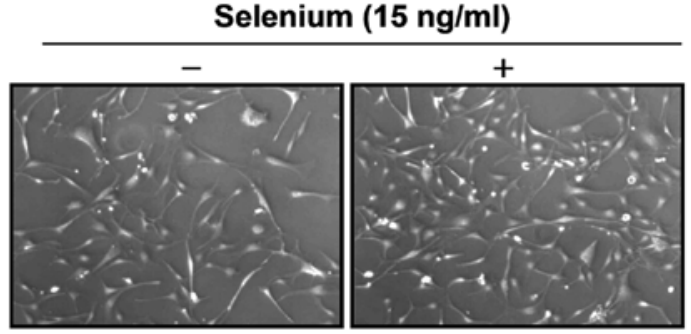

Figure 1. Active cell proliferation of 3T3-L1 preadipocytes by selenium (A) The 3T3-L1 cells were seeded in 6-well plates at a density of $7 \times 10^{4}$ cells per well and stabilized. The medium was then replaced with serum-free DMEM containing different concentrations of selenium. After treatment for the indicated times, the proliferation of the 3T3-L1 cells was evaluated with a trypan blue exclusion assay. The results are expressed as the mean $\pm \mathrm{SD}$ of three independent experiments. The statistical significance of the results was analyzed by a Student's t-test ("p $<0.05$ vs. untreated control). (B) Following treatment for $24 \mathrm{~h}$ with selenium $(15 \mathrm{ng} / \mathrm{ml})$, the density of the seleniumtreated cells was increased in phase-contrast images compared to the control cells.

and the G2/M checkpoint. The CDK1-cyclin B complex is known to regulate $\mathrm{G} 2 / \mathrm{M}$ progression $(16,17)$. In order to investigate the mechanism by which selenium induced the cell proliferation of the 3T3-L1 cells, we focused on the expression of cell cycle-related proteins including CDKs, cyclins, tumor suppressor p53 and CDK inhibitors following the selenium treatment. Our results showed that selenium upregulated the expression of cyclin-dependent kinase 1 (CDK1) and CDK2, without affecting the levels of p53 and cyclins; however selenium markedly downregulated the levels of p21 and p27, which are well-known CDK inhibitors and negatively control a broad range of CDKs (Fig. 3). Taken together, these data suggest that selenium induced active cell proliferation by stimulating cell cycle progression.

Selenium enhances the cell proliferation of 3T3-L1 preadipocytes through the PI3K/Akt pathway. The PI3K/Akt signaling cascade plays a critical role in various physiological processes, including cell cycle progression, transcription, translation, differentiation, apoptosis, and metabolism (18). In particular, the PI3K/Akt pathway is known to control the function of
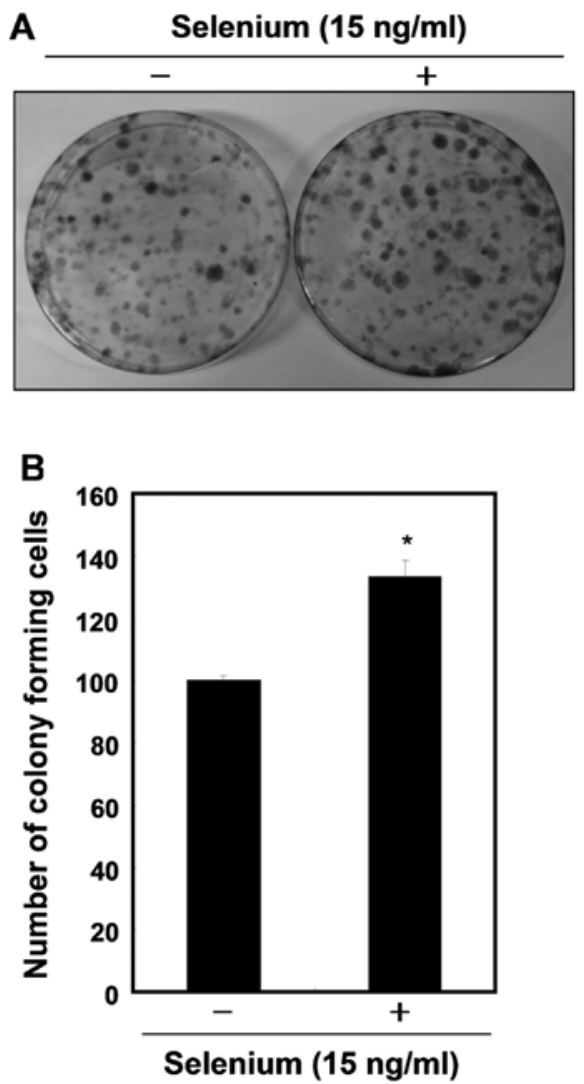

Figure 2. Colony formation of the 3T3-L1 preadipocytes in response to selenium. (A) The cells were seeded in $10-\mathrm{cm}$ cell culture dishes at a density of $3 \times 10^{3}$ and stimulated with selenium $(15 \mathrm{ng} / \mathrm{ml})$ in serum-free DMEM. After incubation for $24 \mathrm{~h}$, the culture media was replaced with fresh media containing $10 \%$ BCS. After 15 days, the culture media was discarded and the attached cells were fixed and stained with $0.1 \%$ toluidine blue $\mathrm{O}$ for 3 days. (B) The proliferation efficiency was determined by visual counting of the colonies. The results are expressed as the mean \pm SD of three independent experiments. The statistical significance of the results was analyzed by a Student's t-test ( ${ }^{*} \mathrm{p}<0.05$ vs. untreated control).

numerous substrates, which regulate cell cycle progression and cellular growth (19). Thus, we hypothesized that selenium stimulates cell growth by modulating the PI3K/Akt signaling pathway. As shown in Fig. 4A, the selenium treatment upregulated PI3K, p-PI3K, and p-Akt, indicating that selenium activates the PI3K/Akt pathway. To confirm that the PI3K/ Akt pathway is important in the cell proliferation induced by selenium, we used LY294002, an inhibitor of PI3K. As we expected, LY294002 not only suppressed the activation of the PI3K/Akt pathway, it also completely blocked the seleniumstimulated cell proliferation (Fig. 4B and C). Collectively, our results demonstrate that the PI3K/Akt signaling pathway plays a crucial role in active cell proliferation of 3T3-L1 cells.

Selenium-induced ERK phosphorylation did not affect the cell proliferation of 3T3-L1 preadipocytes. Extracellular signalrelated kinase (ERK) is a key player in mitogenic signaling following growth factor stimulation, and studies have reported that it functions as a cell survival mechanism against apoptosis $(20,21)$. As many researchers have reported that ERK plays a critical role in cellular proliferation through the Ras/Raf/ MEK/ERK pathway $(22,23)$, we next focused on the activa- 


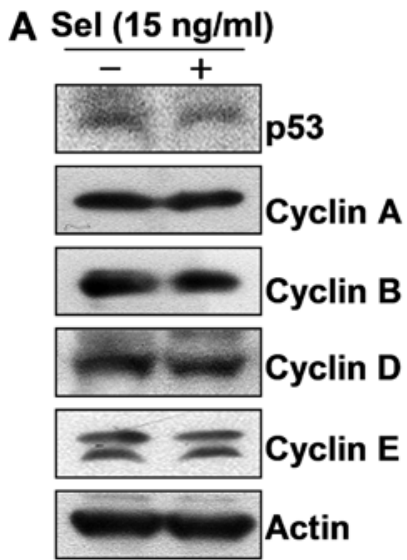

B

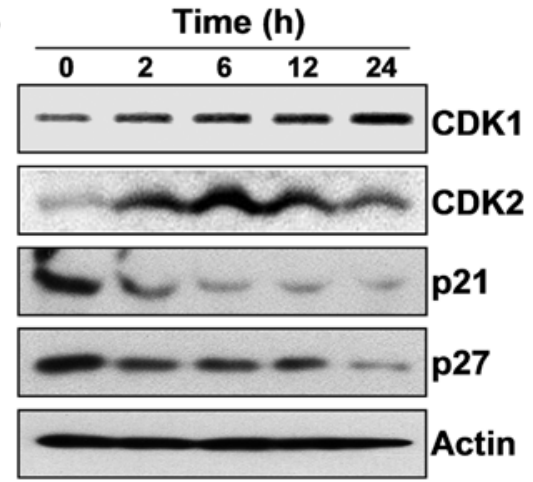

Figure 3. Selenium-induces cell cycle progression of 3T3-L1 preadipocytes. The 3T3-L1 cells were seeded in 10-cm cell culture dishes at a density of 4x10 and stabilized for $24 \mathrm{~h}$. The medium was then replaced with serum-free DMEM containing $15 \mathrm{ng} / \mathrm{ml}$ of selenium and the cells were incubated for $24 \mathrm{~h}$ (A) at the indicated times (B). The cells were then harvested and lysed. The cellular proteins were separated by SDS-polyacrylamide gels and transferred onto nitrocellulose membranes. The membranes were probed with specific primary antibodies against cell cycle-related proteins. The proteins were visualized using an ECL detection system. Actin was used as an internal control.
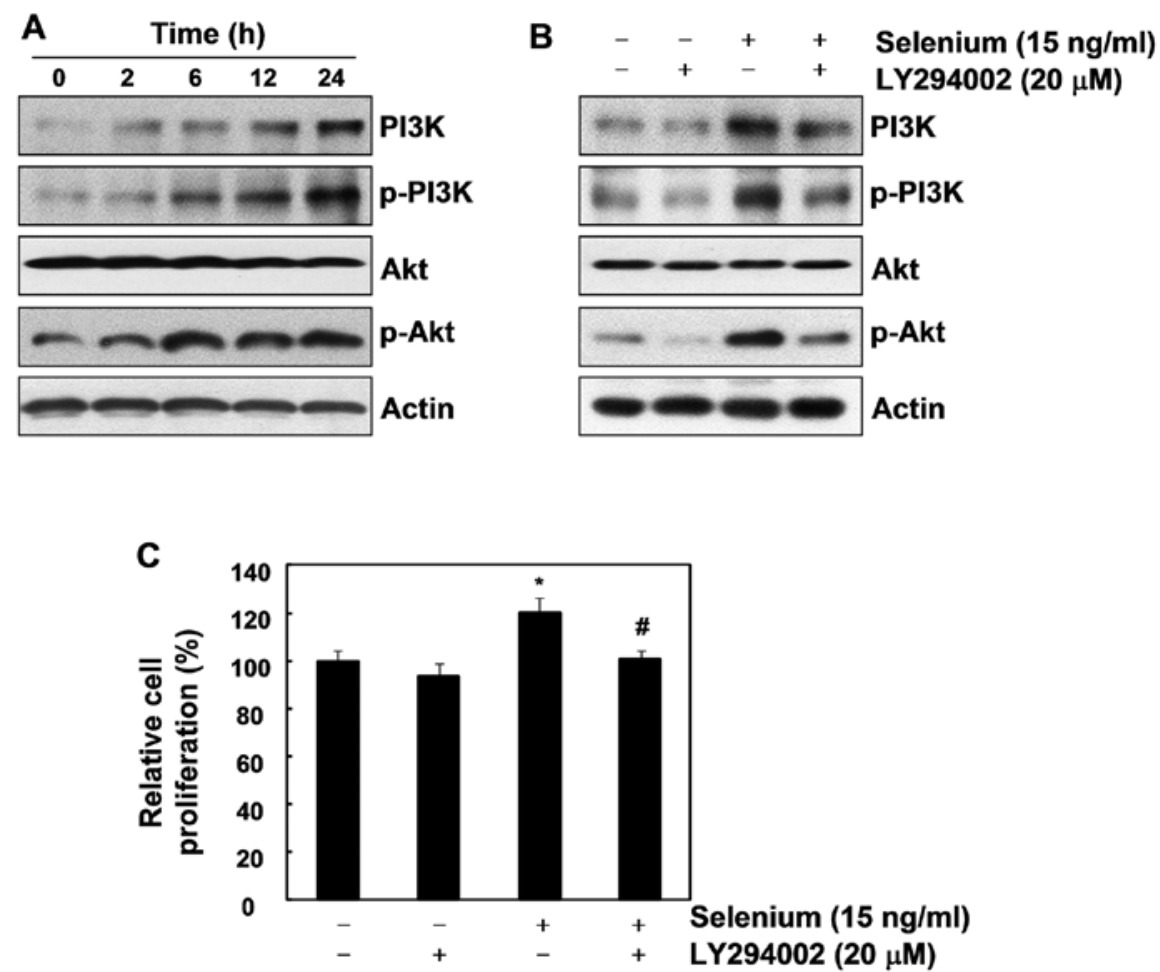

Figure 4. Selenium enhances cell proliferation of the T3-L1 preadipocytes via the PI3K/Akt pathway. The 3T3-L1 cells were seeded in 6-well plates at a density of $7 \times 10^{4}$ cells per well and stabilized for $24 \mathrm{~h}$. (A) The medium was then replaced with serum-free DMEM containing $15 \mathrm{ng} / \mathrm{ml}$ of selenium and the cells were incubated for the indicated times. The cells were then harvested and lysed. The cellular proteins were separated by SDS-polyacrylamide gels and transferred onto nitrocellulose membranes. The membranes were probed with the indicated primary antibodies against the PI3K/Akt signaling pathway. Actin was used as an internal control. (B and C) The cells were pretreated with LY294002 for $2 \mathrm{~h}$ prior to selenium treatment $(15 \mathrm{ng} / \mathrm{ml})$ for $24 \mathrm{~h}$. The expression of the PI3K/Akt signaling pathway was then investigated by western blot analysis (B), and the relative cell proliferation was evaluated with a trypan blue exclusion assay (C). The results are expressed as the mean \pm SD of three independent experiments. The statistical significance of the results was analyzed by a Student's t-test ("p $<0.05$ vs. untreated control; ${ }^{*} \mathrm{p}<0.05$ vs. selenium-treated cells).

tion of ERK. As displayed in Fig. 5A, our data showed that selenium induced ERK phosphorylation in the 3T3-L1 cells. Although the ERK inhibitor PD98059 did not block the active cell proliferation induced by the selenium treatment, it completely inhibited the expression of pERK (Fig. 5B and C).
Taken together, these data suggest that ERK has no effect on the selenium-stimulated cell proliferation of 3T3-L1 cells.

Selenium induces active migration in 3T3-L1 preadipocytes. To assess the migration efficiency of selenium, which is an 

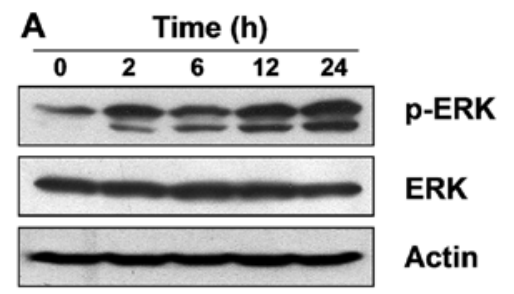

B

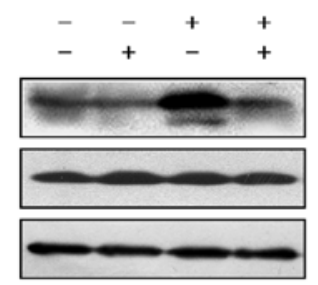

Selenium $(15 \mathrm{ng} / \mathrm{ml})$ PD98059 $(20 \mu \mathrm{M})$

p-ERK

ERK

Actin

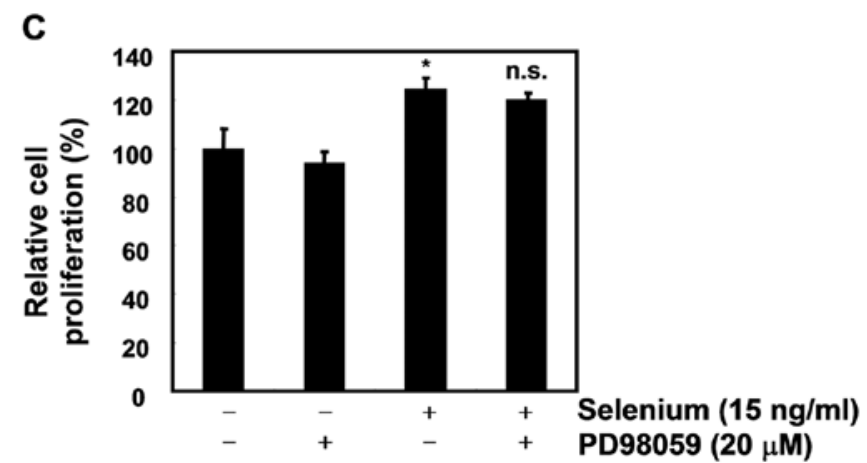

Figure 5. Effect of selenium-induced ERK on the cell proliferation of the 3T3-L1 preadipocytes. The 3T3-L1 cells were seeded in 6-well plates at a density of $7 \times 10^{4}$ cells per well and stabilized for $24 \mathrm{~h}$. (A) The medium was then replaced with serum-free DMEM containing $15 \mathrm{ng} / \mathrm{ml}$ of selenium and cells were incubated for the indicated times. The cells were then harvested and lysed. The cellular proteins were separated by SDS-polyacrylamide gels and transferred onto nitrocellulose membranes. The membranes were probed with the indicated primary antibodies against the ERK pathway. Actin was used as an internal control. (B and C) The cells were pretreated with PD98059 $2 \mathrm{~h}$ prior to selenium treatment $(15 \mathrm{ng} / \mathrm{ml})$ for $24 \mathrm{~h}$. The expression of the ERK pathway was investigated by western blot analysis (B) and the relative cell proliferation was evaluated by a trypan blue exclusion assay (C). The results are expressed as the mean \pm SD of three independent experiments. The statistical significance of the results was analyzed by a Student's t-test ("p<0.05 vs. untreated control; n.s., not significant vs. selenium-treated cells).

A

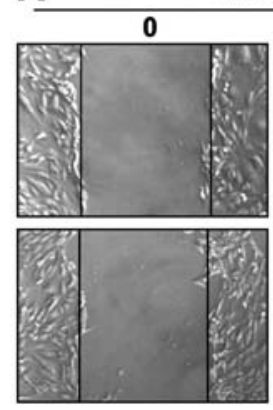

Time (h)
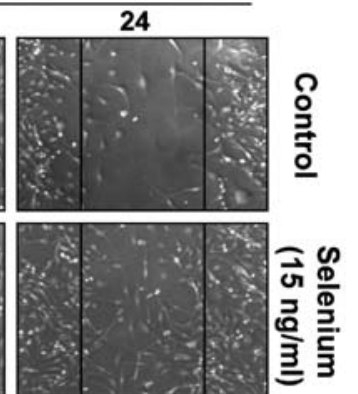

B

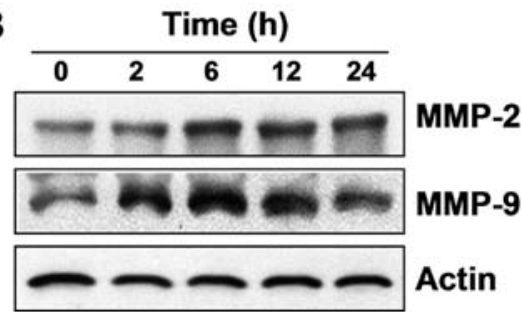

Figure 6. Selenium induced active migration in the 3T3-L1 preadipocytes. (A) To assess the migration efficiency of the selenium-treated 3T3-L1 adipocytes, an in vitro scratch-inducing cell migration assay was conducted. The cells were seeded in $35-\mathrm{mm}$ cell culture dishes at a density of $1.5 \times 10^{5}$ and stabilized for $24 \mathrm{~h}$. They were then scraped in a straight line across the dish and washed with fresh media. After incubation with selenium $(15 \mathrm{ng} / \mathrm{ml})$ for $24 \mathrm{~h}$ in serum-free DMEM, the migrated cells onto the wounded region were photographed under a microscope at $\mathrm{x} 40$ magnification. (B) After incubation with selenium $(15 \mathrm{ng} / \mathrm{ml})$ for the indicated times in serum-free DMEM, the cells were collected, and the cellular proteins associated with cell migration were analyzed by western blot analysis. Actin was used as an internal control. important characteristic of stem cells, an in vitro scratchinducing cell migration assay was conducted. As shown in Fig. 6A, the selenium-treated cells migrated more actively than the control cells, indicating that selenium significantly increased the migration efficiency of the 3T3-L1 cells. Next, we investigated the expression of migration-related proteins, matrix metalloproteinases (MMPs), which have many physiological functions in cell migration and invasion $(24,25)$. Our data showed that selenium upregulated the expression of MMP-2 and MMP-9 in a time-dependent manner. These results indicate that selenium-induced active migration is associated with the overexpression of MMP-2 and MMP-9 (Fig. 6B).

\section{Discussion}

It is hoped that IPSCs will overcome several fundamental problems of stem cell therapy, including ethical issues and the difficulty of obtaining sufficient amounts of adult stem cells. However, many of the underlying mechanisms of the reprogramming processes are unknown, making IPSC technology far from clinical use. Although selenium has been reported to have various pharmacological actions, its ability to improve stem cell behavior has not been fully elucidated. Therefore, we investigated the acquisition of stem cell potency following selenium treatment in 3T3-L1 adipocytes. We also investigated the effects of selenium on the cell proliferation and active migration of the 3T3-L1 adipocytes.

Our data demonstrated that selenium stimulated the cell proliferation of the 3T3-L1 cells, proven by a trypan blue exclu- 
sion assay, microscopic observations and a colony-forming assay. We investigated the mechanisms of selenium-induced active proliferation with respect to cell cycle progression, the PI3K/Akt pathway and ERK phosphorylation. First, we investigated whether selenium modulated the cell cycle regulators of 3T3-L1 cells. Our results showed that selenium upregulated CDK1 and CDK2 and downregulated their inhibitors p21 and p27. Interestingly, selenium did not affect the expression of cyclins, critical regulators of the cell cycle, by forming complexes with CDKs (Fig. 3). Dinarina et al (26) reported that contrary to the common belief, the activation of CDKs does not necessarily depend on cyclins. For example, CDK1 and CDK2 can be directly activated by a protein known as RINGO/Speedy $(14,27)$. Porter et al $(28)$ revealed that the protein can interact with CDK2 and p27 to play a role in the G1/S checkpoint. Thus, our results imply that selenium stimulated cell cycle progression by modulating CDKs, which were activated independently of cyclins.

Second, we focused on the PI3K/Akt and ERK signaling pathways. The PI3K/Akt pathway is activated by growth factors and involved in various biological functions, including cell proliferation, survival and cell migration (18). Several reports have suggested that this signaling pathway plays a crucial role in maintaining the self-renewal activity of ESCs, as well as the dedifferentiation of embryonic germ cells (29-31). Liu et al (32) also reported that an inhibitor of PI3K, LY294002, resulted in the loss of ESC features. Our results also clearly showed that selenium induced active cell proliferation of the 3T3-L1 cells by activating the PI3K/Akt pathway. This was proven by the enhanced expression of $\mathrm{p}-\mathrm{PI} 3 \mathrm{~K}$ and $\mathrm{p}$-Akt, and by the complete inhibition of cell proliferation following LY294002 treatment. As ERK signaling is known to be a key regulator of cell proliferation $(22,23)$, and Kim et al (15) reported that selenium changed adipose-tissue stromal cells into a less mature state via ERK-mediated pathways, we investigated the effect of ERK on the proliferation of the 3T3-L1 adipocytes. However, our results clearly showed that ERK activation did not affect cell proliferation, although selenium induced ERK phosphorylation.

As additional proof of stem cell potency, selenium treatment induced active cell migration, which is an important characteristic of stem cells, in 3T3-L1 cells. The motogenic potential of stem cells is critical in causing the stem cell migration to the wounded area. MMPs seem to play an important role in the active migration of stem cells. Heissig et al (33) demonstrated that MMP-9 enhanced the motogenic potential of stem cells by translocating them to a permissive proliferative vascular niche. In addition, Yu et al (34) reported that MMP-2 promoted the cell migration of mesenchymal stem cells. Our results also showed that selenium upregulated the expression of MMP-2 and MMP-9, both of which are associated with active cell migration of 3T3-L1 cells. We cautiously suggest that selenium-activated ERK might be involved in the active migration of these cells because many researches have reported that ERK is a critical factor in the regulation of cell migration. For example, active MEK promoted cell migration in several cell types, and the mutation or inhibition of ERK suppressed cell migration $(35,36)$.

In conclusion, the present study suggests that selenium can improve the potency of stem cells by stimulating the cellular proliferation and active migration of 3T3-L1 preadipocytes. Our results indicate that regulating the PI3K/Akt pathway might be an attractive method to produce IPSCs. Although future studies will be required to investigate whether selenium stimulates the pluripotency of 3T3-L1 cells to differentiate into various cell types, our results provide knowledge on the novel function of selenium, as well as the molecular mechanisms underlying its activity.

\section{Acknowledgements}

This study was supported by a grant from the National Research Foundation of Korea (NRF) grant funded by the Korea government (2012-0000476), R\&D program of MKE/ KEIT (10040391, Development of Functional Food Materials and Device for Prevention of Aging-associated Muscle Function Decrease), and Blue-Bio Industry RIC at Dong-Eui University as a RIC (08-06-07) program of KIAT under Ministry of Knowledge Economy, Republic of Korea.

\section{References}

1. Aasen T, Raya A, Barrero MJ, Garreta E, Consiglio A, Gonzalez F, Vassena R, Bilić J, Pekarik V, Tiscornia G, Edel M, Boué S and Izpisúa Belmonte JC: Efficient and rapid generation of induced pluripotent stem cells from human keratinocytes. Nat Biotechnol 26: 1276-1284, 2008.

2. Im JE, Song SH, Kim JY, Kim KL, Baek SH, Lee DR and Suh W: Vascular differentiation of multipotent spermatogonial stem cells derived from neonatal mouse testis. Exp Mol Med 44: 303-309, 2012.

3. Taura D, Sone M, Homma K, Oyamada N, Takahashi K, Tamura N, Yamanaka S and Nakao K: Induction and isolation of vascular cells from human induced pluripotent stem cells - brief report. Arterioscler Thromb Vasc Biol 29: 1100-1103, 2009.

4. Pittenger MF, Mackay AM, Beck SC, Jaiswal RK, Douglas R, Mosca JD, Moorman MA, Simonetti DW, Craig S and Marshak DR: Multilineage potential of adult human mesenchymal stem cells. Science 284: 143-147, 1999.

5. Welham MJ, Kingham E, Sanchez-Ripoll Y, Kumpfmueller B, Storm $\mathrm{M}$ and Bone $\mathrm{H}$ : Controlling embryonic stem cell proliferation and pluripotency: the role of PI3K- and GSK-3-dependent signalling. Biochem Soc Trans 39: 674-678, 2011.

6. Lee MY, Lim HW, Lee SH and Han HJ: Smad, PI3K/Akt, and Wnt-dependent signaling pathways are involved in BMP-4induced ESC self-renewal. Stem Cells 27: 1858-1868, 2009.

7. Chen L and Khillan JS: A novel signaling by vitamin A/retinol promotes self renewal of mouse embryonic stem cells by activating PI3K/Akt signaling pathway via insulin-like growth factor-1 receptor. Stem Cells 28: 57-63, 2010.

8. Kimura $\mathrm{T}$ and Nakano T: Induction of pluripotency in primordial germ cells. Histol Histopathol 26: 643-650, 2011.

9. Lee SR, Bar-Noy S, Kwon J, Levine RL, Stadtman TC and Rhee SG: Mammalian thioredoxin reductase: oxidation of the C terminal cysteine/selenocysteine active site forms a thioselenide, and replacement of selenium with sulfur markedly reduces catalytic activity. Proc Natl Acad Sci USA 97: 2521-2526, 2000.

10. Rayman MP: The importance of selenium to human health. Lancet 356: 233-241, 2000.

11. Combs GF and Gray WP Jr: Chemopreventive agents: selenium. Pharmacol Ther 79: 179-192, 1998.

12. Ganther HE: Selenium metabolism, selenoproteins and mechanisms of cancer prevention: complexities with thioredoxin reductase. Carcinogenesis 20: 1657-1666, 1999.

13. Kim JH, Hue JJ, Kang BS, Park H, Nam SY, Yun YW, Kim JS and Lee BJ: Effects of selenium on colon carcinogenesis induced by azoxymethane and dextran sodium sulfate in mouse model with high-iron diet. Lab Anim Res 27: 9-18, 2011.

14. Ferby I, Blazquez M, Palmer A, Eritja R and Nebreda AR: A novel p34cdc2-binding and activating protein that is necessary and sufficient to trigger G2/M progression in Xenopus oocytes. Genes Dev 13: 2177-2189, 1999. 
15. Kim JH, Lee MR, Kim JH, Jee MK and Kang SK: IFATS collection: selenium induces improvement of stem cell behaviors in human adipose-tissue stromal cells via SAPK/JNK and stemness acting signals. Stem Cells 26: 2724-2734, 2008.

16. O'Connor PM, Ferris DK, Pagano M, Draetta G, Pines J, Hunter T, Longo DL and Kohn KW: G2 delay induced by nitrogen mustard in human cells affects cyclin A/cdk2 and cyclin B1/cdc2-kinase complexes differently. J Biol Chem 268: 8298-8308, 1993.

17. Nurse P: A long twentieth century of the cell cycle and beyond. Cell 100: 71-78, 2000.

18. Yuan TL and Cantley LC: PI3K pathway alterations in cancer: variations on a theme. Oncogene 27: 5497-5510, 2008.

19. Steelman LS, Pohnert SC, Shelton JG, Franklin RA, Bertrand FE and McCubrey JA: JAK/STAT, Raf/MEK/ERK, PI3K/Akt and BCR-ABL in cell cycle progression and leukemogenesis. Leukemia 18: 189-218, 2004.

20. Chatani Y, Tanimura S, Miyoshi N, Hattori A, Sato M and Kohno M: Cell type-specific modulation of cell growth by transforming growth factor beta 1 does not correlate with mitogen-activated protein kinase activation. J Biol Chem 270 30686-30692, 1995.

21. Martin P and Pognonec P: ERK and cell death: cadmium toxicity, sustained ERK activation and cell death. FEBS J 277: $39-46,2010$

22. Downward J: Targeting Ras signaling pathways in cancer therapy. Nat Rev Cancer 3: 11-22, 2003.

23. Steelman LS, Chappell WH, Abrams SL, Kempf RC, Long J, Laidler P, Mijatovic S, Maksimovic-Ivanic D, Stivala F, Mazzarino MC, Donia M, Fagone P, Malaponte G, Nicoletti F, Libra M, Milella M, Tafuri A, Bonati A, Bäsecke J, Cocco L, Evangelisti C, Martelli AM, Montalto G, Cervello M and McCubrey JA: Roles of the Raf/MEK/ERK and PI3K/PTEN/ Akt/mTOR pathways in controlling growth and sensitivity to therapy-implications for cancer and aging. Aging (Albany, NY) 3: 192-222, 2011

24. Zhong WD, Han ZD, He HC, Bi XC, Dai QS, Zhu G, Ye YK, Liang YX, Qin WJ, Zhang Z, Zeng GH and Chen ZN: CD147, MMP-1, MMP-2 and MMP-9 protein expression as significant prognostic factors in human prostate cancer. Oncology 75 230-236, 2008

25. Jezierska A and Motyl T: Matrix metalloproteinase-2 involvement in breast cancer progression: a mini-review. Med Sci Monit 15: RA32-RA40, 2009.
26. Dinarina A, Perez LH, Davila A, Schwab M, Hunt T and Nebreda AR: Characterization of a new family of cyclin-dependent kinase activators. Biochem J 386: 349-355, 2005.

27. Lenormand JL, Dellinger RW, Knudsen KE, Subramani S and Donoghue DJ: Speedy: a novel cell cycle regulator of the G2/M transition. EMBO J 18: 1869-1877, 1999.

28. Porter LA, Kong-Beltran M and Donoghue DJ: Spyl interacts with $\mathrm{p} 27^{\mathrm{Kip} 1}$ to allow G1/S progression. Mol Cell Biol 14: 3664-3674, 2003.

29. Paling NR, Wheadon H, Bone HK and Welham MJ: Regulation of embryonic stem cell self-renewal by phosphoinositide 3-kinase-dependent signaling. J Biol Chem 279: 48063-48070, 2004.

30. Watanabe S, Umehara H, Murayama K, Okabe M, Kimura T and Nakano T: Activation of Akt signaling is sufficient to maintain pluripotency in mouse and primate embryonic stem cells. Oncogene 25: 2697-2707, 2006.

31. Kimura T, Tomooka M, Yamano N, Murayama K, Matoba S, Umehara H, Kanai $\mathrm{Y}$ and Nakano T: AKT signaling promotes derivation of embryonic germ cells from primordial germ cells. Development 135: 869-879, 2008.

32. Liu N, Lu M, Feng XM, Ma FX, Fang ZH, Tian XM, Ren Q, Zhang L, Liu B, Huang PP, Liu L and Han ZC: Exogenous Nanog alleviates but is insufficient to reverse embryonic stem cells differentiation induced by PI3K signaling inhibition. J Cell Biochem 106: 1041-1047, 2009.

33. Heissig B, Hattori K, Dias S, Friedrich M, Ferris B, Hackett NR, Crystal RG, Besmer P, Lyden D, Moore MA, Werb Z and Rafii S: Recruitment of stem and progenitor cells from the bone marrow niche requires MMP-9 mediated release of kit-ligand. Cell 109: 625-637, 2002

34. Yu Q, Chen L, You Y, Zou C, Zhang Y, Liu Q and Cheng F: Erythropoietin combined with granulocyte colony-stimulating factor enhances MMP-2 expression in mesenchymal stem cells and promotes cell migration. Mol Med Rep 4: 31-36, 2011

35. Klemke RL, Cai S, Giannini AL, Gallagher PJ, deLanerolle P and Cheresh DA: Regulation of cell motility by mitogen-activated protein kinase. J Cell Biol 137: 481-492, 1997.

36. Jo M, Thomas KS, Somlyo AV, Somlyo AP and Gonias SL: Cooperativity between the Ras-ERK and Rho-Rho kinase pathways in urokinase-type plasminogen activator-stimulated cell migration. J Biol Chem 277: 12479-12485, 2002. 